\title{
Calcium and Vitamin D Supplementation in Elderly Patients with Hip Fractures
}

\author{
Vydehi Veeramalla $^{1}$ and Ashwin Kasturi ${ }^{2 *}$ \\ ${ }^{1}$ Consultant Biochemist, Anupama Hospital, KPHB Colony, Kukutpalli, \\ Hyderabad, Telangana, India \\ ${ }^{2}$ Department of Orthopedics, Mallareddy Institute of Medical Sciences, \\ Hyderabad, Telangana, India \\ *Corresponding author
}

\begin{tabular}{|c|c|}
\hline \multicolumn{2}{|r|}{ A B S T R A C T } \\
\hline & \multirow{7}{*}{$\begin{array}{l}\text { Hip fracture contributes to both morbidity and mortality in the elderly. Adequate levels of } \\
\text { calcium and vitamin } \mathrm{D} \text { are needed to ensure optimum effects of the treatments for } \\
\text { osteoporosis. } 41 \text { elderly patients above the age of } 60 \text { years with low energy hip fractures } \\
\text { were included into the study. After ascertaining the cognition levels, blood was collected } \\
\text { from all the patients for the evaluation of Total calcium and vitamin D. One week after the } \\
\text { operation, the diet of the patients was advised along with the intake of the calcium } \\
1000 \mathrm{mg} / \mathrm{day} \text { for } 12 \text { weeks and vitamin } \mathrm{D} 350,000 \mathrm{IU} / \text { week for } 8 \text { weeks and } 2000 \mathrm{IU} / \mathrm{day} \text { for } \\
\text { next } 4 \mathrm{weeks} \text { as supplements. The mean age for the men was } 79.6 \text { years and in women it } \\
\text { was } 75.7 \text { years. The men were predominantly overweight, with } 5 \text { out of } 12 \text { patients and } 2 \\
\text { were under weight. However, among the women, } 11 \text { out of } 29 \text { patients were overweight } \\
\text { and } 9 \text { obese. The calcium levels in the males before supplements were } 2.1 \pm 0.9 \mathrm{mmol} / 1 \\
\text { and in females it was } 1.9 \pm 0.3 \mathrm{mmol} / 1 \text {. This level increased to } 2.4 \pm 1.2 \mathrm{mmol} / \mathrm{l} \text { and } 2.2 \pm \\
0.9 \mathrm{mmol} / \mathrm{l} \text { respectively after three months of treatment with the supplements. Similarly, } \\
\text { the vitamin } \mathrm{D} \text { levels were } 68 \pm 23 \mathrm{nmol} / \mathrm{l} \text { in males and } 71 \pm 21 \mathrm{nmol} / 1 \text { in females at base } \\
\text { line which increased to } 323 \pm 41 \mathrm{nmol} / 1 \text { and } 329 \pm 45 \mathrm{nmol} / 1 \text { in males and females } \\
\text { respectively after three months of treatment with the supplements. Calcium and vitamin } \mathrm{D} \\
\text { represents a correctable risk factor for fragility fracture in the elderly, possibly specifically } \\
\text { for the hip. }\end{array}$} \\
\hline Keywords & \\
\hline & \\
\hline & \\
\hline Article Info & \\
\hline & \\
\hline & \\
\hline
\end{tabular}

\section{Introduction}

Osteoporosis is a major health problem, especially in elderly populations, and is associated with fragility fractures at the hip, spine, and wrist. Hip fracture contributes to both morbidity and mortality in the elderly. Because of its complications, which include chronic pain, disability, diminished quality of life, and premature death, this is considered to be one of the major health problems of the elderly in the West as well as a growing problem in Asia (Mithal et al., 2009). With the life expectancy growing throughout the world, the number of the elderly persons is estimated to rise from 1.66 million in 1990 to 6.26 million by 2050 (Cooper et al., 1992).

The incidence of hip fractures varies across the different countries of the world. It is found to be highest in Sweden and North America, while in the Asian and the Latin American 
countries, it is found to be less. However, since the density of population is higher in Asia, by 2050, the incidence of hip fractures is estimated to contribute more than $50 \%$ in the world (Cooper et al., 1992).

Half of all women will eventually suffer from a fracture after the age of 50, while the same is estimated to occur for $25 \%$ of all males at the same age (Keen et al., 2007). Thus, the prevention of osteoporosis has become of utmost importance. It has been shown that identification and management of patients at risk can significantly reduce the risk of a further fracture through modification of life style, adequate treatment of osteoporosis, and a falls prevention programme (Fisher et al., 2006; Parker.et al., 2000). Most current osteoporosis guidelines assume that patients who receive treatment for secondary prevention of osteoporotic fragility fractures have an adequate calcium intake and are vitamin $\mathrm{D}$ replete. Adequate levels of calcium and vitamin $\mathrm{D}$ are needed to ensure optimum effects of the treatments for osteoporosis and are recommended in the data sheets of all the commonly used drugs.

Vitamin D status is best evaluated by measuring the circulating 25-hydroxyvitamin D concentration in the serum. A level of 75 $\mathrm{nmol} / \mathrm{L}$ or above is the general accepted for optimal circulating 25-hydroxyvitamin D level (Bischoff-Ferrari et al., 2004). Low calcium levels increase parathyroid hormone (PTH) production by the parathyroid glands. This stimulates calcium release from the bones and increases the reabsorption of calcium in the distal renal tubule cells. PTH also stimulates the renal production of biologically active vitamin $\mathrm{D}$, which in turn increases calcium absorption from the gut. All these actions increase the calcium level in plasma. High calcium levels on the other hand stimulate the thyroid gland to produce and release calcitonin, which inhibits bone resorption by blocking PTH receptors on the osteoclasts, decreases calcium reabsorption in the kidney, and decreases calcium absorption from the gut. Thus reducing plasma calcium levels (Andy De Jong et al., 2013).

Vitamin D deficiency may be characterized biochemically by the presence of secondary hyperparathyroidism, which can also contribute to the bone loss in osteopenic patients. Secondary hyperparathyroidism is a physiological response to hypocalcaemia associated with vitamin D deficiency, and treatment with vitamin $\mathrm{D}$ will normalise the elevated PTH levels without significantly elevating the serum calcium level(Andy De Jong et al., 2013).In the general population, particularly in the elderly, vitamin D levels are commonly reduced as a result of low dietary intake, decreased sun exposure, decreased intrinsic vitamin $\mathrm{D}$ production, and decreased vitamin D receptor activity (Tangpricha et al., 2002).

This study was conducted for the purpose of observing the levels of calcium and vitamin D levels before and after the treatment with supplements in elderly patients with hip fractures.

\section{Materials and Methods}

This study was conducted by the department of Biochemistry and Orthopedics of Anupama Hospital, Hyderabad during the period of One year. 41 elderly patients above the age of 60 years with low energy hip fractures who had come to our hospital for management were included into the study. The hip fractures for all of these patients were caused by fall from the same level as the patient.

After obtaining the clearance from the Institutional ethical committee, the details of the study were explained to the patients and Informed consent was obtained from all of 
them. Patients with multifractures, fractures other than hip, patients under 65 years of age and high energy fractures were excluded from the study. Patients who were not cognitive or unable to communicate were also excluded from the study.

The cognitive function of the patients was assessed using the Mild-mental state examination (MMSE) questionnaire with 10 questions, including for orientation to time and place, repeating named prompts, registration recall, phrase repetition, drawing of interlocking figures etc. A total of 30 points was given to the questionnaire and any score greater or equal to 24 points indicated normal cognition (Folstein et al., 1975).

Demographic details including the age, height, weight was noted for all the patients and the nutritional status was evaluated by calculating the body mass index. Blood was collected from all the patients used for the evaluation of serum Total calcium and serum vitamin D. Calcium was estimated using the o-cresolphthale in complex one method. Vitamin D was estimated using 25(OH) vitamin D ELISA (SIGMA) method.

One week after the operation, the diet of the patients was advised along with the intake of the calcium $1000 \mathrm{mg} /$ day for 12 weeks and vitamin D3 50,000IU/week for 8 weeks and 2000IU/day for next 4 weeks as supplemtents. Mean values for all the variables was calculated and student $t$ test was performed to compare the means. A $p$ value of $<0.05$ was considered to be significant.

\section{Results and Discussion}

Out of the 41 patients, $29(70.7 \%)$ were women and 12 (29.3\%) were men (Fig. 1). Cervical hip fractures was observed in 23 $(56.1 \%)$ patients and trochanteric hip fractures was seen in 18 (43.9\%) (Fig. 2).
The mean age for the men was 79.6 years and in women it was 75.7 years. The men were predominantly overweight, with 5 out of 12 patients and 2 were under weight. However, among the women, 11 out of 29 patients were overweight and 9 obese (Table 1).

The calcium levels in the males before supplements were $2.1 \pm 0.9 \mathrm{mmol} / \mathrm{l}$ and in females it was $1.9 \pm 0.3 \mathrm{mmol} / \mathrm{l}$. This level increased to $2.4 \pm 1.2 \mathrm{mmol} / \mathrm{l}$ and $2.2 \pm 0.9$ $\mathrm{mmol} / \mathrm{l}$ respectively after 3 months of treatment with the supplements.

Similarly, the vitamin D levels were $68 \pm$ $23 \mathrm{nmol} / 1$ in males and $71 \pm 21 \mathrm{nmol} / 1$ in females at base line which increase to $323 \pm$ $41 \mathrm{nmol} / \mathrm{land} 329 \pm 45 \mathrm{nmol} / 1$ in males and females respectively after 3 months of treatment with the supplements (Table 2).

Vitamin D is a fat soluble and it controls the absorption of calcium from the intestines and its use in bone mineralization and also provides immunity (Harinarayan et al., 2005). A lack of vitamin $D$ leads to impaired mineralisation of bone, with the development of rickets in children or osteomalacia in adults apart from autoimmune disorders, cardiovascular disorders, various cancers, diabetes, hypertension, osteoporosis and fractures in bones (Holick et al., 2005).

The recommended daily intake of vitamin $\mathrm{D}$ is 600 IU. About $90 \%$ of the daily recommended intake is obtained from the action of sunlight on the skin. Exposure of the face and arms for 20-30 minutes per day will be sufficient, although sunscreens of Factor 10 and above will block the synthesis of vitamin $\mathrm{D}$ by the skin. The remaining $10 \%$ of our vitamin $\mathrm{D}$ is supplied by diet. Good sources of vitamin D include fortified margarine and cereal, egg yolk and oily fish. During the winter months in the UK, vitamin $\mathrm{D}$ is only available from the diet, and there is 
a risk of deficiency in those who have inadequate intake (Grant et al., 2005).

Calcium is also essential for bone health. The Government's committee on the Medical Aspects of Food and Nutrition Policy (COMA), has recommend that the Reference Nutrient Intakes (RNI) for adults should be above $700 \mathrm{mg} /$ day to be compatible with bone health in the normal population If a patient has been diagnosed with osteoporosis, calcium intake may be increased to approximately $1200 \mathrm{mg} /$ day for adults. Extra calcium levels may be taken as part of the diet or given as a supplement, although it is recommended that the daily intake from all sources should not exceed more than 2000$2500 \mathrm{mg}$ of calcium per day as higher levels may have a detrimental effect on health (MHSO, 1988). A general consensus of 1,200 $\mathrm{mg} / \mathrm{day}$ levels of calcium may slow the rate of bone loss (Tang et al., 2007)

Fig.1 Age wise distribution of the patients

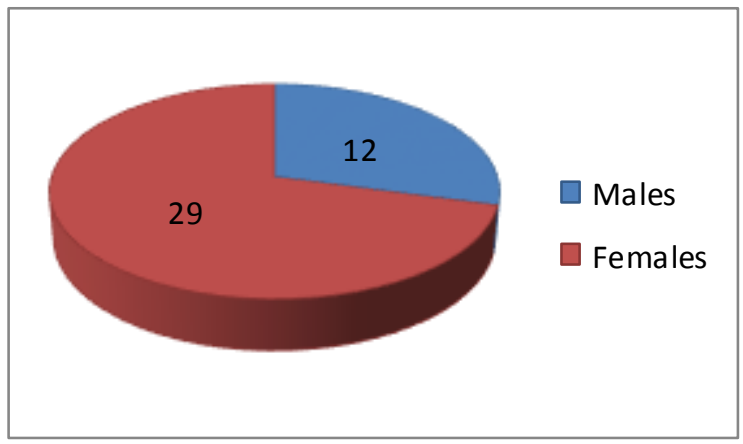

Fig.2 Types of fractures

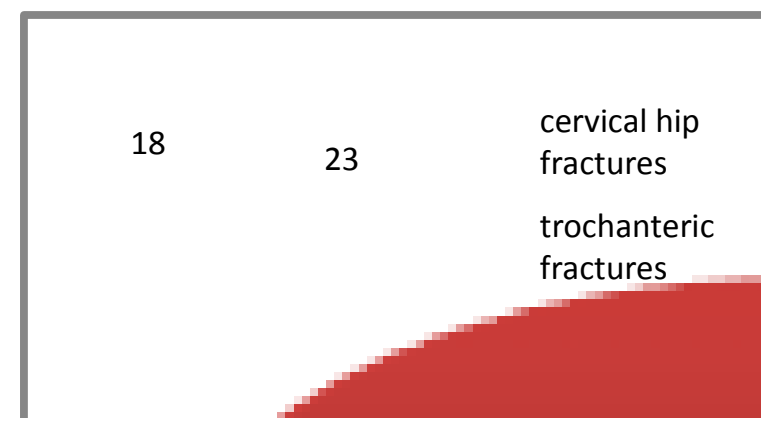

Table.1 Demographic details of the patients

\begin{tabular}{|l|l|l|}
\hline Variables & Males & Females \\
\hline Age (Years) & $79.6 \pm 8.1$ & $75.7 \pm 5.9$ \\
\hline BMI $\left(\mathrm{kg} / \mathrm{m}^{2}\right)$ & $27 \pm 3.9$ & $29 \pm 4.6$ \\
\hline Underweight (acc to BMI) & $2(16.7 \%)$ & $5(17.2 \%)$ \\
\hline Normal (acc to BMI) & $4(33.3 \%)$ & $4(13.8 \%)$ \\
\hline Overweight (acc to BMI) & $5(41.7 \%)$ & $11(37.9 \%)$ \\
\hline Obese (acc to BMI) & $1(8.3 \%)$ & $9(31.0 \%)$ \\
\hline
\end{tabular}


Table.2 Biochemical parameters of the patients

\begin{tabular}{|l|l|l|l|}
\hline Biochemical parameters & Males & Females & Total \\
\hline $\begin{array}{l}\text { Ca }(\mathrm{mmol} / \mathrm{l}) \\
\text { Before supplements }\end{array}$ & $2.1 \pm 0.9$ & $1.9 \pm 0.3$ & \\
After supplements & $2.4 \pm 1.2^{*}$ & $2.2 \pm 0.9^{*}$ & $2.0 \pm 0.5$ \\
\hline $\begin{array}{l}\text { Vit D(nmol/l) } \\
\begin{array}{l}\text { Before supplements } \\
\text { After supplements }\end{array}\end{array}$ & $68 \pm 23$ & $71 \pm 21$ & $2.3 \pm 1.3^{*}$ \\
\hline $\begin{array}{l}\text { No of Vit D deficient } \\
\text { patients }(<75 \mathrm{nmol} / \mathrm{l})\end{array}$ & $11(91.7 \%)$ & $27(93.1 \%)$ & $68 \pm 22$ \\
\hline
\end{tabular}

*: $\mathrm{p}<0.05$

It has been observed that there is a reduction in the incidence of fractures on treatment with calcium alone, but treatment with vitamin $\mathrm{D}$ supplementation, there is a further reduction of 37\% (Shea et al., 2002; Papadimitropoulos et al., 2002).

In the present study, the number of females with hip fractures was more than the number of males. The mean age of the patients in the study was $79.6 \pm 8.1$ in males and $75.7 \pm 5.9$ in females. The calcium levels in the males before supplements were $2.1 \pm 0.9 \mathrm{mmol} / \mathrm{l}$ and in females it was $1.9 \pm 0.3 \mathrm{mmol} / \mathrm{l}$. These levels increased to $2.4 \pm 1.2 \mathrm{mmol} / \mathrm{l}$ and $2.2 \pm$ $0.9 \mathrm{mmol} / \mathrm{l}$ respectively after 3 months of treatment with the supplements in males and females respectively.

Similarly, the vitamin D levels were $68 \pm 23$ $\mathrm{nmol} / \mathrm{l}$ in males and71 $\pm 21 \mathrm{nmol} / \mathrm{l}$ in females at base line which increase to $323 \pm 41 \mathrm{nmol} / 1$ and $329 \pm 45 \mathrm{nmol} / 1$ in males and females respectively after 3 months of treatment with the supplements. In the retrospective study by Gallacher et al., (2005) the mean age was 80.5 years, 94\% were aged over 60 and $74 \%$ patients aged over 75 . The mean vitamin $\mathrm{D}$ level was $24.7 \mathrm{nmol} / \mathrm{L}(9.9 \mathrm{ng} / \mathrm{ml})$, with 97.8\% patients having vitamin $\mathrm{D}$ levels below $70 \mathrm{nmol} / \mathrm{L}$ and $91.6 \%$ having vitamin D levels below $50 \mathrm{nmol} / \mathrm{L}$. As with our study, there were no significant differences by patient age or presentation of fracture. In yet another study, vitamin D insufficiency (plasma $25 \mathrm{OHD}<50 \mathrm{nmol} / \mathrm{l}$ ) was observed in $81 \%$ of the patients and the average plasma 25OHD was $41 \mathrm{nmol} / \mathrm{l}$ (Moosgaard et al., 2005).

The number of cervical hip fractures was more in the patients especially in females compared to the intertrochanteric fractures. Similar case was reported by another study by Peng-Fei Li, where patients with femoral neck fractures were more common compared to the intertrochanteric fractures (Peng-Fei Li et al., 2016). Since the hip fracture is a complex feature which involves many factors, a proper strategy to secure adequate and standardized perioperative treatment is important (Ayus et al., 2012; Khalili et al., 2012; Chen et al., 2014; Uzoigwe et al., 2014).

However, Calderazzi et al., (2014) found that osteoarthritis strongly affects the location of the fracture in the proximal femur. Larrosa $e t$ al., (2012) compared 128 patients with femoral neck fractures and 196 patients with femoral intertrochanteric fractures, and found the neck fractures to be more common.

With the treatment of the patients with the calcium and the vitamin D3 supplements, an improvement in the levels of the calcium and vitamin D3 levels have been observed which are estimated to reduce the bone loss of the 
patient. Only calcium treatment is said to have a very small positive effect on the bone density (Shea et al., 2007). It is also said to have a very small role to play in substantially reducing the fracture risk (Kanis et al., 2005; Winzenberg et al., 2006). Some studies have suggested no correlation between the calcium intake and the osteoporotic hip fracture (Tavani et al., 1995; Michaelsson et al., 2003).

The effect of vitamin D alone in fracture prevention is also unclear (Avenell et al., 2005), though, one study reports no association with fracture risk (Michaelsson et al., 2003). However, in the present study, a combination of calcium as well as Vitamin D3, has shown to have a positive effect on the bone density and reduction on the bone loss. Chapuy et al., (1992) reported that calcium with vitamin D (1000 mg of calcium and 800 IU of vitamin D per day) significantly reduced the risk of hip and nonvertebral fractures among elderly women who were believed to be vitamin $\mathrm{D}$ - deficient.

In a multi centric study by Dukas et al., (2004) in patients who were treated with only Vit D3, had more number of falls as compared to those who were treated with calcium also. It is estimated that vitamin D has a positive effect on the bone regeneration through its endocrine activity on the calcium homeostasis, thereby increasing the supply of $\mathrm{Ca}$ for fracture regeneration (Carmeliet et al., 2015).

Calcium and Vitamin D deficiency are common findings seen in elderly patients with hip fractures. With proper treatment, the levels of both these substances rise to the normal levels thereby decreasing the incidence of fractures. Thus, Calcium and vitamin $\mathrm{D}$ represents a correctable risk factor for fragility fracture in the elderly, possibly specifically for the hip.

\section{References}

Andy De Jong, Kate Woods, Lise Van Gestel, Mohanraj Suresh, Matthew Porteous. Vitamin D insufficiency in osteoporotic hip fracture patients: Rapid substitution therapy with high dose oral cholecalciferol (vitamin D3). Acta Orthop. Belg., 2013, 79: 578-586.

Avenell A, Gillespie WJ, Gillespie LD, O'Connell DL. Vitamin D and vitamin D analogues for preventing fractures associated with involutional and postmenopausal osteoporosis. Cochrane Database Syst Rev. 2005; 3: CD000227.

Ayus JC, Negri AL, Kalantar-Zadeh K, et al., Is chronic hyponatremia a novel risk factor for hip fracture in the elderly? Nephrol Dial Transpl. 2012; 27: 37253731.

Bischoff-Ferrari HA, Dietrich T, Orav EJ, Dawson Hughes B. Positive association between 25-hydroxy vitamin D levels and bone mineral density: a population based study of younger and older adults. Am J Med 2004; 116: 634-639.

Calderazzi F, Groppi G, Ricotta A, et al., Does hip osteoarthritis has a protective effect against proximal femoral fractures? A retrospective study. Hip Int. 2014; 24: 231-236.

Carmeliet, G., Dermauw, V. and Bouillon, R. Vitamin D signaling in calcium and bone homeostasis: a delicate balance. Best practice and research. Clinical Endocrinology and Metabolism. 29: 621-631 (2015).

Chapuy MC, Arlot ME, Duboeuf F, Meunier PJ. Vitamin D3 and calcium to prevent hip fractures in elderly women. N Engl J Med 1992; 327: 1637-42.

Chen YJ, Kung PT, Wang YH, et al., Greater risk of hip fracture in hemodialysis than in peritoneal dialysis. Osteoporos Int. 2014; 25: 1513-1518.

Committee on Medical Aspects of Food and 
Nutrition Policy. Nutrition and bone health with particular reference to calcium and vitamin D. MHSO, London 1998.

Cooper C, Campion G, Melton LJ., 3rd Hip fractures in the elderly: A world-wide projection. Osteoporos Int. 1992; 2: 285-9

Dukas L, Bischoff HA, Lindpaintner LS, et al., Alfacalcidol reduces the number of fallers in a community-dwelling elderly population with a minimum calcium intake of more than $500 \mathrm{mg}$ daily. $\mathrm{J} \mathrm{Am}$ Geriatr Soc. 2004; 52(2): 230-236

Fisher AA, Davis MW, Rubenach SE et al., Outcomes for older patients with hip fractures: the impact of orthopedic and geriatric medicine cocare. J Orthop Trauma 2006; 20: 172-178

Folstein MF, Folstein SE, McHugh PH. Mini Mental Test/MMT. J Psychiatr Res. 1975; 12: 189-98.

Gallacher SJ, McQuillian C, Harkness M, Finlay F, Gallagher AP, Dixon T.Prevalence of vitamin D inadequacy in Scottish adults with non-vertebral fragility fractures. Curr Med Res Opin. 2005 Sep; 21(9): 1355

Grant AM, Avenell A, Campbell MK et al., Oral vitamin D3 and calcium for secondary prevention of low-trauma fractures in elderly people (Randomised Evaluation of Calcium or Vitamin D, RECORD): a randomised placebocontrolled trial. Lancet. 2005; 365: 1621-8.

Harinarayan CV. Prevalence of vitamin D insufficiency in postmenopausal south Indian women. Osteoporos Int. 2005; 16: 397-402.

Holick MF. The Vitamin D Epidemic and its Health Consequences. J Nutr 2005; 135: 2739S-48S.

Kanis JA, Johansson H, Oden A, DeLaet C, Johnell O, Eisman JA, et al., A metaanalysis of milk intake and fracture risk: low utility for case finding. Osteoporos Int. 2005; 16: 799-804.

Keen R. Osteoporosis: strategies for prevention and management. Best Pract Res Clin. 2007; 21: 109-22.

Khalili H, Huang ES, Jacobson BC, et al., Use of proton pump inhibitors and risk of hip fracture in relation to dietary and lifestyle factors: a prospective cohort study. BMJ. 2012; 344-372.

Larrosa M, Gomez A, Casado E, et al., Hypovitaminosis D as a risk factor of hip fracture severity. Osteoporos Int. 2012; 23: 607-614.

Michaelsson K, Melhus H, Bellocco R, Wolk A. Dietary calcium and vitamin D intake in relation to osteoporotic fracture risk. Bone. 2003; 32: 694-703.

Mithal A, Dhingra V, Lau E. Beizing, China: An International Osteoporosis Foundation (IOF) publication; 2009. The Asian audit: Epidemiology, costs and burden of osteoporosis in Asia.

Moosgaard B, Vestergaard P, Heickendorff L, Melsen F, Christiansen P, Mosekilde L. Vitamin D status, seasonal variations, parathyroid adenoma weight and bone mineral density in primary hyperparathyroidism. Clin Endocrinol (Oxf). 2005 Nov; 63(5): 506-13.

Papadimitropoulos E, Wells G, Shea B, et al., Meta-analyses of therapies for postmenopausal osteoporosis. VIII. Meta-analyses of the efficacy of vitamin D treatment in preventing osteoporosis in postmenopausal women. Endocr Rev 2002; 23: 560- 9.

Parker MJ, Pryor GA, Myles J. 11-year results in 2,846 patients of the Peterborough Hip Fracture Project: reduced morbidity, mortality and hospital stay. Acta Orthop Scand 2000; 71: 34-38

Peng-Fei Li, Zi-Ling Lin, Zhi-Hui Pang, YiRong Zeng. Does serum calcium relate to different types of hip fracture? A 
retrospective study. Chinese Journal of Traumatology 19(2016): 275-277.

Shea B, Wells G, Cranney A, et al., Metaanalyses of therapies for postmenopausal osteoporosis. VII. Meta-analysis of calcium supplementation for the prevention of postmenopausal osteoporosis. Endocr Rev 2002; 23: 552-9.

Shea B, Wells G, Cranney A, Zytanuk N, Robinson V, Griffith L, et al., Calcium supplementation on bone loss in postmenopausal women. Cochrane Database Syst Rev. 2007; 18: CD004526.

Tang BM, Eslick GD, Nowson C, Smith C, Bensoussan A. Use of calcium in combination with vitamin D supplementation to prevent fractures and bone loss in people aged 50 years and older: a meta-analysis. Lancet. 2007; 370: 657-66.

Tangpricha V, Pearce EN, Chen TC, Holick MF. Vitamin D insufficiency among free-living healthy young adults. Am J Med 2002; 112: 659-662.

Tavani A, Negri E, La Vecchia C. Calcium, dairy products, and the risk of hip fracture in women in Italy. Epidemiology. 1995; 6: 554-7.

Uzoigwe CE, Khan A, Smith RP, et al., Hypothermia and low body temperature are common and associated with high mortality in hip fracture patients. Hip Int. 2014; 24: 237-242.

Winzenberg T, Shaw K, Fryer J, Jones G. Effect of calcium supplementation on bone density in healthy children metaanalysis of randomised controlled trails. Br Med J. 2006; 333: 7572-754.

\section{How to cite this article:}

Vydehi Veeramalla and Ashwin Kasturi. 2017. Calcium and Vitamin D Supplementation in Elderly Patients with Hip Fractures. Int.J.Curr.Microbiol.App.Sci. 6(12): 2983-2990. doi: https://doi.org/10.20546/ijcmas.2017.612.348 